\title{
Forming Judgments of Attitude Certainty, Intensity, and Importance: The Role of Subjective Experiences
}

\author{
G eoffrey H addock \\ University of Exeter, England
}

\author{
Alexander J. Rothman \\ University of M innesota \\ Rolf Reber \\ University of Berne, Switzerland \\ N orbert Schwarz \\ University of M ichigan
}

Two studies examined the impact of subjective experiences on reports of attitudecertain ty, inten sity, and importance In Study 1, participants with moderate or extreme attitudes toward doctor-assisted suicide generated three (easy) or seven (hard) arguments that either supported or countered their opinion toward theissueprior to in dicating thestren gth of their attitude. Participants with moderate attitudes rated their opinions as more intense, personally important, and held with greater certainty when they had generated either a small number of supporting arguments or a large number of opposing arguments. Ratings provided by individuals with extreme attitudes were unaffected by the argument gen eration task. In Study 2, the impact of ease of recall on stren gth-related judgmen ts was eliminated when it was ren dered non diagn ostic by a misattribution manipulation. Implications of these findings for attitude strength and other judgmental phen omena are discussed.

$\mathbf{E}$ veryday experience suggests that we feel more strongly about some topics than others. Within social psychology, this observation is reflected in numerous attempts to specify the "strength" associated with an attitude. Since early discussions by Allport and Hartman (1925), the topic of attitude strength has been of considerable interest to attitude researchers and has been addressed under various headings, including attitude "intensity, centrality, salience, certainty, ego-involvement, importance, confidence, crystallization, [and] ambivalence" (Schuman \& Presser, 1981, pp. 231-232). The strength with which a person holds an attitude has a number of important implications for predicting both the stability of an attitude and the likelihood that an individual will choose to act on an attitude ( see Petty \& Krosnick, 1995). For instance, important attitudes are more stable over time (Krosnick, 1988), and attitudes based on direct experience are more likely to guide behavior (Fazio \& Zanna, 1978). Given that the strength of people'sattitudescan affect their cognition and their behavior, Krosnick and Abelson (1992) have argued that investigators need to measure both the direction and the strength of people's attitudes.

Although research has increased our understanding of the concept of attitude strength, our understanding of the processes underlying how people determine the strength of their attitudesisless developed (cf. Downing, Judd, \& Brauer, 1992; Fazio, 1995; Roese \& Olson, 1994; see also Festinger, 1957). How do people respond to questionsdesigned to assessstrength-related properties?

\footnotetext{
Authors' N ote: This research was partially supported by a U niversity of Exeter Research Grant to the first author and a Swiss National Science Foundation Fellowship to the third author. We wish to thank John Bassili and three anonymous reviewers for their comments on an earlier draft of this article. Wealso wish to thank Dan H rubes, AmyKnife, Amy Lee, Lori Siegel, and Elizabeth Wooley for assistance with data collection. Address correspondence to Geoffrey Haddock, Department of Psychology, U niversity of Exeter, Exeter EX 4 4Q G, England; e-mail G. H addock@exeter.ac.uk.

PSPB, Vol. 25 No. 7, July 1999 771-782

(C) 1999 by the Society for Personality and Social Psychology, Inc.
} 
Are these judgments stable over time, or are they sensitive to features of the situation in which theyare formed? Given the apparent utility of distinguishing between people who hold "strong" and "weak" attitudes, these would appear to be important questions. The studies reported in this article identify one variable that influencesjudgments of attitude strength-related properties. Specifically, we demonstrate that the ease with which attitude-relevant information comes to mind can alter people's perceptions of their own attitudes.

\section{THE CONCEPT OF ATTITUDE STRENGTH}

As other researchers have noted, the concept of attitude strength is not easily defined (Bassili, 1996b; Krosnick \& Petty, 1995; Raden, 1985). The term is generally used to describe attitudes that are (a) more persistent over time, (b) more resistant to change, (c) more likely to influence information processing and judgments, and (d) more likely to guide behavior (Krosnick \& Petty, 1995).

A number of attitudinal attributes have been used to differentiate between strong versus weak attitudes. In a comprehensive review, Krosnick, Boninger, Chuang, Berent, and Carnot (1993) identified 10 different dimensions that have been examined in previous research: extremity, intensity, certainty, importance, interest, knowledge, accessibility, direct experience, latitudes of rejection, and affective-cognitive consistency. Krosnick et al. (1993) demonstrated that these indices do not represent a single latent construct. M ore recently, Krosnick and Petty ( 1995) have organized these dimensions into four broad categories. Some dimensions of attitude strength are attributes of the attitude itself. For instance, attitude extremity is operationalized as the degree of deviation of an attitude from the midpoint of an attitude scale (Abelson, 1995). Other dimensions of attitude strength are based on the cognitive structure of an attitude. For instance, the amount of knowledge an individual possesses about a to pic, the accessibility of an attitude, and the level of ambivalence associated with an attitude are all concerned with the strength of associative links among an individual's evaluations and cognitions. O ther dimensions of attitude strength are derived from an individual's subjective beliefs about their attitudes. For instance, people care about some attitudes more than others; this dimension is referred to as attitude importance (Krosnick, 1988). Similarly, people have subjective beliefs about the intensity with which they hold an attitude as well as how certain or confident they are in their position. Finally, Krosnick and Petty (1995) have identified a dimension that emphasizes the elaborative processes through which an attitude is organized. These categories highlight the fact that different factors can contribute to the strength of an atti- tude and are consistent with the premise that different dimensions may be associated with different patterns of results (Krosnick \& Schuman, 1988).

Our interest in the topic of attitude strength was motivated by a desire to understand how people respond to questions designed to assess strength-related properties and the extent to which such reports might vary as a function of the subjective experiences that accompany the accessibility of attitude-relevant information. Asa result, we were primarily interested in how individuals might derive responses to questions that measure those operationalizations that Krosnick and Petty (1995) labeled subjective beliefs (e.g., attitude certainty, intensity, and importance).

THE DERIVATION OF SUBJECTIVE REPORTS OF ATTITUDE STRENGTH

Recent research and theorizing suggests that subjective beliefs or reports of attitude strength can vary as a function of the context in which the judgment is provided. For instance, Bassili (1993, 1996a, 1996b) has stated that individuals typically do not have ready-made assessments of the strength of their attitudes, a position consistent with the assertion that subjective belief dimensions of attitude strength are malleable. In his research, Bassili (1993, 1996a, 1996b) has offered the distinction between operative and meta-attitudinal measures of attitude strength. Bassili (1993) defined operative indices as "direct manifestations of the information processing involved in an attitude judgment" (p. 55). Response latency (see Fazio, 1995) is a prime example of an operative index of attitude strength. Bassili (1993) defined meta-attitudinal indices as those that require respondents to "reflect on their attitudes and report their "impressions" of it" (p. 56). Bassili (1993) classified attitude certainty, intensity, and importance as examples of meta-attitudinal indices of attitude strength. In a series of studies, Bassili (1993, 1996b) has explored the distinction between operative and metaattitudinal indices of attitude strength and whether these different classes of measuresare differentially reactive. As predicted, Bassili has found that operative and meta-attitudinal measures form distinct clusters, that operative measures account for unique variance in attitude pliability and stability, and that meta-attitudinal measureswere poorer predictors of the relation between people'sattitudesand behavior. In line with the primary thesis of the present research, Bassili (1996b) stated that "under most circumstances, people do not have direct access to ready-made assessments of how strong their attitudes are" ( p. 639) and that "meta-attitudinal measures are particularly susceptible to extraneous influences" (p. 637). These conclusions are consistent with the proposal tested in this article: Reports of sub- 
jective or meta-attitudinal indices of attitude strength may differ as a function of the subjective experiences that accompany the retrieval of attitude-relevant information.

Research by Roese and Olson (1994) is also consistent with the proposal that reports of attitude strength-related dimensions can vary as a function of the context in which theyare provided. Roese and OIson examined whether the frequency of attitude expression affects reports of attitude importance (cf. Krosnick, 1988). They observed that the repeated expression of an attitude heightened people's perceptions of its importance. Roese and OIson (1994) interpreted their findings by suggesting that perceivers may "use the ease with which attitudinal information comes to mind as a heuristic cue for inferring perceived attitude importance" (pp. 46-47). Although Roese and OIson's (1994) study did not explicitly test the notion that ease of retrieval can be used as a cue to infer subjective judgments of attitude strength, more recent research has started to directly investigate this question.

THE ROLE OF SUBJECTIVE EXPERIENCES

ON ATTITUDE STRENGTH JUDGMENTS

Although investigators have long assumed that judgments can be affected by the ease with which information comes to mind, direct evidence of this effect has only recently been provided. In research derived from T versky and Kahneman's (1973) work on the availability heuristic, Schwarz et al. (1991, Study 1) asked a group of participants to recall either 6 or 12 instances in which they behaved assertively. Pretesting revealed that recalling 6 examples was easy, whereas retrieving 12 instances was difficult. After completing this behavior-recollection task, participants then rated their own assertiveness. If judgments are determined by the con tent (i.e., number) of recalled behaviors, one would predict higher ratings of assertiveness among those asked to recall 12 behaviors. In contrast, if, as Schwarz et al. (1991) predicted, judgments are determined by the subjective experience of ease associated with the retrieval task, one would predict higher ratings of assertivenessamong those asked to recall 6 behaviors. The results supported Schwarz et al.'s (1991) prediction, suggesting that people can rely on the subjective ease with which information comes to mind in forming judgments.

We believe that subjective ease of retrieval may serve as a source of information that individuals might use in deriving reports of attitude certainty, intensity, and importance. Consistent with this proposal, two studies have demonstrated that ease of retrieval influences subjective reports of attitude strength. In one study, $\mathrm{Had}$ dock, Rothman, and Schwarz (1996) asked participants to generate either three or seven arguments that either supported or opposed their attitude toward doctorassisted suicide. Participantsfound it easy to recall three arguments but difficult to recall seven. After completing this task, participants rated the certainty, intensity, and importance of their attitude toward the issue. If participants used the ease or difficulty with which they could bring the material to mind as a source of information, they should report greater certainty, intensity, and importance after recalling three rather than seven supporting arguments or recalling seven rather than three opposing arguments. The results were consistent with thisprediction: Participants reported that their attitudes were stronger when they had experienced either an easy time retrieving supporting arguments or a difficult time retrieving opposing arguments.

Wänke, Bless, and Biller (1996) have also observed that ease of retrieval affects attitude-based judgments. In this study, participants' attitudes about the use of public transportation were more favorable after having had an easy time generating supporting arguments or a hard time generating counterarguments toward the issue. Of interest to our research, participantsfelt more confident about their attitude after having had an easy time generating supporting arguments.

Taken together, the findings reported by H addock et al. (1996) and Wänke et al. (1996) indicate that subjective judgments of attitude strength are affected by the ease (or difficulty) associated with generating either supporting or counterarguments from memory. In the present research, our goal was to replicate and extend these findings by (a) considering a variable that might moderate the impact of subjective experiences on judgments of attitude certainty, intensity, and importance and (b) providing evidence that bears directly on the role of experienced ease of retrieval as a mediator of these effects. In our first study, we examined whether the extremity of an individual's preexisting attitude would moderate the impact of subjective experiences on reports of attitude certainty, intensity, and importance. We hypothesized that ease of retrieval effects would be limited to individuals with a moderate attitude toward our target issue. In our second study, we included a misattribution manipulation that led some participantsto discount the diagnosticity of their subjective experience. Following from research by Schwarz et al. (1991, Study 3), we expected that participants would draw on their subjective experience only when it was diagnostic.

STUDY 1: ATTITUDE EXTREMITY, EASE OF RETRIEVAL, AND ATTITUDE STRENGTH JUDGMENTS

Although research by Haddock et al. (1996) and Wänke et al. (1996) has documented that subjective judgments of attitude strength can rest on the ease or dif- 
ficulty with which attitude-relevant arguments come to mind, it isnot the onlytype of information on which people can base strength-related judgments. Three lines of reasoning suggest that the impact of subjective experiences on judgments of attitude certainty, intensity, and importance might differ as a function of the extremity of an individual's attitude.

A first line of reasoning rests on the distinction between operative and meta-attitudinal indices of attitude strength (Bassili, 1993, 1996a, 1996b). Metaattitudinal indices of attitude strength, such as certainty, intensity, and importance, are generally not represented in memory. H owever, people who have extensive experience with an issue and have had reason to repeatedly express their attitude on that issue may develop a memorial representation of these strength-related properties and thus may have more direct access as to whether their attitude is intense, important, and held with greater certainty (see Bassili, 1996a, 1996b). We would suggest that these individuals are more likely to hold extreme than moderate attitudes. As a result, judgments of only individualswith moderate attitudesshould be affected bythe context in which the judgment is formed.

Second, reliance on the relative ease with which information comes to mind can be considered a heuristic judgmental strategy, and previous research suggests that individuals are more likely to rely on heuristic strategies when the task is less involving and personally relevant (Chaiken, Liberman, \& Eagly, 1989; Eagly \& Chaiken, 1993; Petty \& Cacioppo, 1986; Rothman \& Schwarz, 1998). For example, Rothman and Schwarz asked men with or without a family histor y of heart disease to recall few or many behaviors that increase or decrease their personal risk of heart disease. Rothman and Schwarz found that ease of retrieval effects were limited to men without a family history of heart disease. These individuals, for whom the issue wasless personally relevant, relied on their recall experiences when they subsequently assessed their own vulnerability to heart disease. Specifically, they reported higher vulnerability after recalling a few (easy) rather than many (difficult) risk-increasing factors and after recalling many rather than a few riskdecreasing factors. Consistent with dual-process models of information processing (see Chaiken \& Trope, in press) , these findings suggest that reliance on subjective accessibility experiences is particularly likely when the task is not very involving. Given the documented finding that topics about which individuals hold moderate attitudes are less involving to the individual compared to topics on which they hold extreme attitudes ( see Leippe \& Elkin, 1987; Thomsen, Borgida, \& Lavine, 1995), we would predict that individuals who hold moderate attitudes are more likely to rely on their subjective experiences.
A third line of reasoning is based on the finding that individuals are more committed to extreme (compared to moderate) attitudes and that individuals highly committed to their attitudes are less likely to change their opinions (e.g., Johnson \& Eagly, 1989; Kiesler, 1971; Krosnick, 1988). Consistent with this observation, a number of studies have revealed that thinking about the reasons underlying one's attitude produces attitude change, but particularly among individuals with less crystall lized attitudes (e.g., H odges \& Wilson, 1993; Wilson, Kraft, \& Dunn, 1989).

Taken together, these three lines of reasoning (and research underlying their assumptions) support the prediction that the ease associated with generating attituderelevant arguments would influence judgments of attitude certainty, intensity, and importance made by individuals who held moderate attitudes. Although individuals with extreme attitudes were expected to provide higher ratings of attitude certainty, intensity, and importance as compared to those with moderate attitudes, the judgments of individuals with extreme attitudes should be unaffected by the relative ease with which attituderelevant arguments come to mind.

\section{METHOD}

\section{Participants and Design}

Participants were 80 students recruited from an introductory psychology subject pool. The study took the form of a 2 (argument type: supporting arguments vs. counterarguments) $\times 2$ (argument number: three vs. seven arguments) $\times 2$ (prior attitude: moderate vs. extreme attitude) between-subjectsdesign. ${ }^{1}$ Participants were randomly assigned to one level of the first two manipulated variables ( see below for how participants were categorized as possessing extreme versus moderate attitudes).

\section{$M$ aterials and Procedure}

Selection of participants. Participants were selected on the basis of their responses to a mass-testing questionnaire administered at the beginning of the academic term. Among the measures they completed in the pretest questionnaire was a question concerning their attitude toward doctor-assisted suicide. Respondents indicated their attitude toward the issue on a 7-point scale ( 1 = I am strongly opposed to doctor-assisted suicide, $7=1$ am strongly in favor of doctor-assisted suicide). Thirty-eight participants whose response to the pretest question placed them at either of the scale's endpoints served as the extreme attitude group in our study. Of these individuals, 20 held extremely positive attitudes (i.e., they were strongly in favor of the issue), and 18 held extremely negative attitudes. Within each of these groups, 
TABLE 1: Q uestions U sed to Assess Attributes of Attitude Strength

1. How certain are you about your attitude toward the issue of doctor-assisted suicide? (certainty)

2. How firm is your opinion toward the issue of doctor-assisted suicide? (certainty)

3. How intense is your attitude toward the issue of doctor-assisted suicide? (intensity)

4. How strong is your attitude toward the issue of doctor-assisted suicide? (intensity)

5. How important is your attitude toward the issue of doctor-assisted suicide to you personally? (importance)

6. How much does your attitude toward the issue of doctor-assisted suicide mean to you? (I mportance)

approximately half of the participants generated argumentsthat spoke in favor of the issue, whereasthe others generated arguments that spoke against the issue. As a result, approximately half of the extreme attitude participants provided arguments that supported their attitude, whereas the others provided arguments that countered their attitude. ${ }^{2}$

The moderate attitude participants in our study ( $n=$ 42) responded to the pretest item by reporting that they were either "somewhat in favor of (or opposed to) doctor-assisted suicide." Of these individuals, 20 reported moderately positive attitudes, and 22 reported moderately negative attitudes. Within each of these groups, approximately half of the participants generated arguments that spoke in favor of the issue, whereas the others generated arguments that spoke against the issue. Once again, these procedures insured that approximately half of the moderate attitude participants provided arguments that supported their attitude, whereas the others provided arguments that countered their attitude.

Experimental session. Participants arrived to the laboratory in groups of 2 to 7 for a study on "social issues." The cover page of the experimental booklet informed participants that we were interested in understanding students' thoughts about allowing doctors to assist in the suicide of terminally ill patients. On the next page, participants were told that we were interested in the reasons or arguments that people on both sides of the issue might use in a discussion about the topic. They were then asked to provide three (or seven) arguments that spoke in favor of (or against) the issue. After completing this task, participants completed questions assessing the certainty, intensity, and importance of their attitude toward doctor-assisted suicide. These questions were the same as those used by Haddock et al. (1996) and were adapted from Krosnick et al. ( 1993). Two questionswere used to measure each of the dimensions (see Table 1). For each question, participants were asked to provide on a 7-point scale the degree to which their attitude was intense, important, and held with certainty ( $1=$ not at all intense, important, certain, etc., 7 = very intense, important, certain, etc.). On completing these questions, participants reported how difficult they found the argument generation task ( $1=$ not at all difficult, $7=$ very difficult).
N ext, participants rated whether each generated argument supported or countered their attitude (this was done to ensure that participants properly followed the instructions) as well as how convincing each generated argument was ( $1=$ not at all convincing, $7=$ very convincing). Finally, participants in the three-argument condition were asked to generate four additional arguments before providing demographic information. Participants in the seven-argument condition completed only the demographic questions at this stage of the study. All participants were debriefed as to the nature of research, thanked, and dismissed.

\section{RESULTS}

\section{$M$ anipulation Checks}

To ensure that the difficulty associated with the arguments generation task differed between the three- and seven-argument conditions, we compared participants' difficulty ratings. As expected, participants found it easier to generate three $(M=3.48)$ ascompared to seven $(M=$ 5.03) arguments, $F(1,72)=15.03, p<.001$. There wasal so a significant main effect of argument type. Participants who generated supporting arguments reported less difficulty $(M=3.81)$ than did people who generated counterarguments $(M=4.74), F(1,72)=5.36, p<.05$. No other effects approached significance.

To ensure that the quality of the argumentsgenerated did not differ across conditions, we examined how convincing participants found the arguments that they had generated. As a measure of convincingness, we took the average of the ratings participants provided for their last two arguments (see Haddock et al., 1996). An AN OVA revealed that the last two arguments generated by participants in the seven-argument condition were rated as convincing asthe second and third arguments generated by participants in the three-argument condition $(F<1)$. This finding is important, because the extent to which generating many arguments is difficult. Those generated near the end of the task might be less convincing, providing a possible alternative explanation for a shift in certainty, intensity, and importance ratings. The sole significant effect in this analysis was a main effect of argument type, $F(1,59)=9.60, p<.05$. Participants who provided arguments that supported their opinion rated 
their last two arguments as more convincing ( $M=4.72$ ) than did participants who provided opposing arguments ( $M=3.64)$.

\section{Judgments of Attitude Strength}

Asin the study of $\mathrm{H}$ addock et al. (1996), judgments of certainty, intensity, and importance were combined to form a composite index of attitude strength $(\alpha=.91)$. $^{3}$ Because investigators frequently assess these dimensions independently, we also report separate analyses for the certainty, intensity, and importance measures.

Composite measure. The analysis on the composite measure revealed a main effect of prior attitude, $F(1,72)=$ $22.02, p<.001$. As expected, individuals with extreme attitudes ( $M=5.60$ ) rated their attitudesasstronger than did participants with moderate attitudes $(M=4.40)$. $\mathrm{H}$ owever, this effect was qualified by a marginally significant three-way interaction, $F(1,72)=3.19, p=.07$. As expected, responses of participants with moderate attitudes differed as a function of the ease or difficulty they experienced in generating supporting or opposing arguments. The left-hand side of the top panel of Table 2 presents the mean judgments made by individuals with moderate attitudes. As can be seen, participants who provided arguments that supported their position judged their attitude as stronger after having generated three ( $M=5.04$ ) as compared to seven $(M=4.11)$ arguments. Conversely, participants who provided arguments that countered their position judged their attitude asstronger after having generated seven $(M=4.55)$ ascompared to three ( $M=3.82)$ arguments. Thispattern of means is reflected by a significant argument type by argument number interaction, $F(1,72)=4.74, p<.05$, and is consistent with our hypothesis that subjective experiences would influence judgments made by individuals with moderate attitudes.

The right-hand side of the top panel presents the mean judgments made by individuals with extreme attitudes. As can be seen, there were no differences among judgments as a function of argument number and argument type.

A ttitu de certain ty. The analysis on the certainty measure revealed a main effect of prior attitude, $F(1,72)=$ $30.52, p<.001$. As expected, individuals with extreme attitudes ( $M=6.12$ ) held their attitudes with greater certaintythan did participants with moderate attitudes $(\mathrm{M}=$ 4.52). H owever, this effect was qualified by a marginally significant three-way interaction, $F(1,72)=3.10, p=.08$. Further analyses revealed that the responses of participants with moderate attitudes differed as a function of argument type and argument number, $F(1,72)=3.06, p=$ .08. As can be seen in the second panel of Table 2, the pattern of means is consistent with what would be
TABLE 2: Judments of Attitude Strength as a Function of Argument Type Argument N umber, and Attitude Extremity, Study 1

\begin{tabular}{|c|c|c|c|c|}
\hline \multirow{4}{*}{$\begin{array}{l}\text { Argument } \\
\text { Type }\end{array}$} & \multicolumn{4}{|c|}{ Attitude Extremity } \\
\hline & \multicolumn{2}{|c|}{ M oderate } & \multicolumn{2}{|c|}{ Extreme } \\
\hline & Three & Seven & Three & Seven \\
\hline & Arguments & Arguments & Arguments & Arguments \\
\hline \multicolumn{5}{|c|}{ Composite measure } \\
\hline Supporting & 5.04 & 4.11 & 5.52 & 5.42 \\
\hline Counter & 3.82 & 4.55 & 5.87 & 5.60 \\
\hline \multicolumn{5}{|c|}{ Attitude certainty } \\
\hline Supporting & 5.33 & 4.09 & 5.72 & 5.90 \\
\hline Counter & 4.15 & 4.39 & 6.67 & 6.20 \\
\hline \multicolumn{5}{|c|}{ Attitude intensity } \\
\hline Supporting & 5.04 & 4.05 & 5.61 & 5.10 \\
\hline Counter & 3.40 & 4.94 & 5.89 & 5.65 \\
\hline \multicolumn{5}{|c|}{ Attitude importance } \\
\hline Supporting & 4.75 & 4.18 & 5.17 & 5.25 \\
\hline Counter & 3.60 & 4.33 & 5.06 & 4.95 \\
\hline
\end{tabular}

NOTE: Higher scores represent higher ratings.

expected if individuals used their subjective experience as a source of information. In contrast, the responses of participants with extreme attitudes did not differ across conditions.

Attitudeintensity. The analysison the intensity measure revealed a main effect of prior attitude, $F(1,72)=16.55$, $p<.001$. As expected, individuals with extreme attitudes ( $M=5.55$ ) rated their attitudes as more intense than did participants with moderate attitudes $(M=4.37)$. However, this effect was qualified by a significant three-way interaction, $F(1,72)=3.75, p=.05$. Further analyses revealed that the responses of participants with moderate attitudes differed as a function of argument type and argument number, $F(1,72)=9.86, p<.01$. Ascan be seen in the third panel of Table 2 , the pattern of means is consistent with what would be expected if individuals used their subjective experience as a source of information. In contrast, the responses of participants with extreme attitudes did not differ across conditions.

Attitude importance. The analysis on the importance measure revealed a main effect of prior attitude, $F(1,72)=$ $9.79, p<.01$. As was obser ved for ratings of attitude intensity and certainty, individuals with extreme attitudes ( $M=$ 5.11) rated their attitudes as more important than did participants with moderate attitudes ( $M=4.24)$. Although the three-way interaction was not significant, $F(1,72)=1.73, p=.19$, the pattern of responses among people with moderate and with extreme attitudes was consistent with our predictions. As can be seen in the bottom panel of Table 2, people with moderate attitudes appeared to rely on the ease with which information came to mind, whereas people with extreme attitudes were unaffected by the generation task. 


\section{DISCUSSION}

The results of the study confirmed the hypothesis that accessibility experiences affect subjective reports of attitude strength-related properties, but only among participants with moderate attitudes. The findings are consistent with Bassili's (1996a, 1996b) proposal that individuals with moderate attitudes do not have direct access to meta-attitudinal (i.e., subjective) judgments about the strength of their attitudes. Furthermore, our results are consistent with research that has examined the impact of analyzing reasons on attitude change (Hodges \& Wilson, 1993).

Although the results obtained in Study 1, along with those obtained by Haddock et al. (1996) and Wänke et al. (1996), indicate that subjective experiences associated with the generation of supporting or counter arguments can affect subjective judgments of strength-related properties, the hypothesized mediator has not been tested directly. If these findingsare indeed mediated by an individual's subjective experience during recall, the inclusion of a misattribution manipulation designed to undermine the diagnosticity of the subjective experience should produce different effects.

STUDY 2: MISATTRIBUTION, EASE OF RETRIEVAL, AND ATTITUDE STRENGTH JUDGMENTS

The objective of Study 2 was to obtain direct evidence for the role of accessibility experiences as a mediator of our findings. To accomplish thisgoal, we used a misattribution paradigm that has been used successfully in prior research to demonstrate the mediating effect of ease of retrieval on judgment ( Rothman \& H ardin, 1997, Study2; Schwarz et al., 1991, Study3). For example, Schwarz et al. (1991, Study3) observed that participants onlyrelied on their subjective experience of ease or difficulty of retrieval when its diagnosticity was not called into question. In their study, Schwarz et al. asked participants to recall 6 (easy) or 12 (difficult) examples of assertive behaviors and informed participants that music played during the recall task might render recall easy (or difficult). As expected, participants relied on their recall experience only when the alleged side effect of the music contradicted these experiences, thus rendering them diagnostic. Under high diagnosticity, participants judged themselves as more assertive after recalling 6 rather than 12 examples of their own assertive behaviors. However, when the alleged side effect of the music matched participants' experiences, thus rendering them nondiagnostic, participants based their assertiveness judgments on the content of recall and reported higher assertiveness after recalling 12 rather than 6 examples of assertive behaviors.
We adapted this paradigm for our second study. Similar to our first study, participants in Study 2 were asked to generate either three or seven arguments that either supported or countered their attitude toward doctorassisted suicide. However, participants completed this task while listening to a selection of music. Some participants were led to believe that the music would facilitate thought, whereas other participants were led to believe that the music would inhibit thought. Learning that the music would facilitate thought should reduce the diagnosticity associated with having had an easy time generating three arguments. Similarly, learning that the music would inhibit thought should reduce the diagnosticity associated with having a difficult time generating seven arguments. The remaining combinations of these variables (learning that music inhibits thought but having had an easy time generating three arguments or learning that music facilitates thought but having had a hard time generating seven arguments) should lead participants to conclude that their subjective experience was highly diagnostic.

Consistent with the findings of Schwarz et al. (1991, Study 3), we expected our participants to draw on the ease of their recall experience when its diagnosticity was not called into question but to draw on the content of what they recalled when their subjective experience was rendered nondiagnostic.

\section{METHOD}

\section{Participants}

Participants were 78 students ( 40 females, 38 males) recruited from the introductory psychologysubject pool and randomly assigned to condition in a 2 (argument type: supporting vs. counter arguments) $\times 2$ (argument number: three vs. seven arguments) $\times 2$ (diagnosticity: high vs. low diagnosticity of experienced ease of recall) between-subjects design. ${ }^{4}$

$M$ aterials and Procedure

Participants came to the laboratoryin groups of three to seven for a study on "music and reasoning." Theywere misinformed that past research had revealed that listening to certain types of music strongly facilitates or inhibits thought and that during the experimental session they would be asked to complete a task while listening to a selection of music. On the cover page of the experiment booklet, participants were provided with four pieces of information about their musical selection. The first three pieces of information were constant across participants. All participants learned that the music would play throughout the session, would be a classical selection, and would be played at a medium level of volume. The fourth piece of information provided the 
misattribution manipulation. Some participants learned that the music would have the impact of facilitating recall, whereas the remaining participants learned that the music would inhibit recall.

After reading this information, the music was started and participants proceeded with the task. Similar to Study 1, the task instructions indicated that we were interested in understanding students' attitudes toward allowing doctors to assist in the suicide of terminally ill patients. First, participants reported their attitude toward the issue on a 7-point scale ( $1=$ bad, 7 =good). O n the next page, participants were instructed that we were interested in the reasons or arguments that people on both sides of the issue might use in a discussion about the topic. They then generated three (or seven) arguments that spoke in favor of (or against) their attitude. After finishing this task, participants completed the attitude certainty, intensity, and importance questions. On completing these questions, participants rated the difficulty of the argument generation task and answered a series of questions concerning the musical selection (these were included to provide further rationale for the cover story). N ext, participants rated whether each generated argument supported or countered their attitude and the convincingness of each generated argument. At this point, participantsin the three-argument condition generated four additional arguments before providing demographic information. Participants in the sevenargument condition only completed the demographic questions. Finally, participants were debriefed as to the nature of research, thanked, and dismissed.

\section{RESULTS}

\section{M anipulation Checks}

To ensure that ease of retrieval differed between the three- and seven-argument conditions, we compared participants' difficulty ratings. As expected, participants found it easier to generate three ( $M=3.54$ ) ascompared to seven $(M=5.00)$ arguments, $F(1,70)=15.21, p<.001$. No other effects approached significance.

Asin Study 1, we al so examined whether the self-rated convincingness of participants' arguments differed as a function of our manipulations. An ANO VA revealed that participants in the three- and seven-argument conditions did not differ in the ratings of their last two arguments. The ANOVA did reveal a significant main effect of argument type, $F(1,53)=17.55, p<.01$. Participants who provided arguments that supported their opinion rated their last two arguments as more convincing ( $M=$ 4.81) than did participants who provided opposing arguments ( $M=3.52)$. There was also a main effect of diagnosticity, $F(1,53)=7.63, p<.05$. Participants whose experience was highly diagnostic rated their last two arguments as more convincing $(M=4.50)$ than did participantswho provided opposing arguments $(M=3.91)$.

Judgments of Attitude Strength

Asin Study 1, we present the data collapsed across all questions $(\alpha=.90)$ and separately for attitude certainty, intensity, and importance.

Compositemeasure. A $2 \times 2 \times 2$ ANOVA yielded a significant three-wayinteraction, $F(1,70)=5.85, p<.02$. Ascan be seen in the left-hand side of the top panel of Table 3 , when the diagnosticity of the subjective experience was high, participantsused thisexperience asinformation in deriving their judgments. This is reflected by a marginally significant two-way interaction, $F(1,70)=3.06, p=$ .09. When asked to provide supporting arguments, participants reported greater attitude certainty, intensity, and importance after having generated three $(M=5.05)$ rather than seven ( $M=4.02$ ) arguments. In contrast, when asked to report counter arguments, participants reported greater strength after having generated seven ( $M=4.08)$ rather than three $(M=3.77)$ arguments.

The pattern was opposite, however, when the alleged effects of the music rendered the subjective experience noninformative. As can be seen in the right-hand side of the top panel, when the diagnosticity of the subjective experience was low, the results suggest that participants used the content of recalled information in making their strength judgments. This is reflected by a marginally significant two-way interaction, $F(1,70)=3.34, p=.07$. When asked to provide supporting arguments, participants reported greater certainty, intensity, and importance after having generated seven $(M=4.35)$ rather than three ( $M=3.61)$ arguments. In contrast, when asked to report counterarguments, participants reported greater strength after having generated three ( $M=4.11)$ rather than seven ( $M=3.70)$ arguments.

Attitudecertainty. A $2 \times 2 \times 2$ ANOVA yielded a significant three-wayinteraction, $F(1,70)=5.89, p<.02$. Ascan be seen in the second panel of Table 3 , when the diagnosticity of the subjective experience was high, participants used this experience as information in making their certainty judgments. This is reflected by a marginally significant two-way interaction, $F(1,70)=3.63, p=$ .06. In contrast, when the diagnosticity of the subjective experience was low, the results suggest that participants used the content of recalled information in making their judgments. This is reflected by a marginally significant two-way interaction, $F(1,70)=2.58, p=.12$.

Attitude intensity. A $2 \times 2 \times 2$ ANOVA yielded a significant three-wayinteraction, $F(1,70)=7.50, p<.01$. Ascan be seen in the third panel of Table 3, when the diagnosticity of the subjective experience was high, participants used this experience as information in deriving intensity 
TABLE 3: Judgments of Attitude Strength as a Function of Argument Type, Argument N umber, and Diagnosticity: Study 2

\begin{tabular}{|c|c|c|c|c|}
\hline \multirow{4}{*}{$\begin{array}{l}\text { Argument } \\
\text { Type }\end{array}$} & \multicolumn{4}{|c|}{ Diagnosticity } \\
\hline & \multicolumn{2}{|c|}{$\mathrm{High}$} & \multicolumn{2}{|c|}{ Low } \\
\hline & Thre & Seven & Three & Seven \\
\hline & Arguments & Arguments & Arguments & Arguments \\
\hline \multicolumn{5}{|c|}{ Composite measure } \\
\hline Supporting & 5.05 & 4.02 & 3.61 & 4.35 \\
\hline Counter & 3.77 & 4.08 & 4.11 & 3.70 \\
\hline \multicolumn{5}{|c|}{ Attitude certainty } \\
\hline Supporting & 5.36 & 4.28 & 4.03 & 5.06 \\
\hline Counter & 4.13 & 4.55 & 4.68 & 4.17 \\
\hline \multicolumn{5}{|c|}{ Attitude intensity } \\
\hline Supporting & 5.00 & 3.94 & 3.43 & 4.28 \\
\hline Counter & 3.31 & 3.90 & 4.05 & 3.50 \\
\hline \multicolumn{5}{|c|}{ Attitude importance } \\
\hline Supporting & 4.79 & 3.83 & 3.37 & 3.72 \\
\hline Counter & 3.88 & 3.80 & 3.59 & 3.44 \\
\hline
\end{tabular}

NOTE: Higher scores represent higher ratings.

judgments. This is reflected by a significant two-way interaction, $F(1,70)=4.40, p<.05$. In contrast, when the diagnosticity of the subjective experience was low, the results suggest that participants used the content of recalled information in making their strength judgments. This is reflected by a significant two-way interaction, $F(1,70)=3.97, p=.05$.

Attitu deimportance. A $2 \times 2 \times 2$ AN OVA failed to yield a significant three-way interaction, $F(1,70)=1.52, p=.22$. H owever, the means in both the high and low diagnosticity conditions were in the expected direction (see the bottom panel of Table 3).

\section{DISCUSSION}

The results of Study 2 provided direct evidence for the role of accessibility experiences as a mediator of our previous findings. Individuals who believed that their subjective experience was diagnostic relied on this information in deriving their judgment. In contrast, when participants were induced to discount their subjective experience, they relied on the content of the information they had brought to mind. These results are consistent with those obtained by Schwarz et al. (1991, Study3) and provide strong evidence in support of the impact of accessibility experiences on subjective judgments of strength-related properties.

\section{GENERAL DISCUSSION}

Although there has been a considerable amount of research about differences between strong and weak attitudes (e.g., Petty \& Krosnick, 1995), we have a poorer understanding of how people determine whether an attitude is important, intense, or certain. The present research sought to determine the extent to which subjective experiences associated with the retrieval of attituderelevant information from memory would affect these judgments. Recent research (e.g., $\mathrm{H}$ addock et al., 1996; Wänke et al., 1996) has suggested that some reports of attitude strength are indeed influenced by the ease associated with the retrieval of argumentsthat are relevant to the target attitude object. The present research was designed to replicate and extend these findings by (a) considering a variable that might moderate the impact of subjective experiences on attitude strength-related judgments and (b) providing evidence directly supporting the role of the subjective ease of retrieval as a mediator of these results.

The primary purpose of Study 1 was to determine whether the impact of subjective experiences on judgment would be moderated by an individual's preexisting attitude toward the attitude issue. Based on the premise that individuals with extreme attitudes are more likely to have summary assessments of strength represented in memory (Bassili, 1996a, 1996b) as well as the prediction derived from dual-process models of attitude change (e.g., Chaiken et al., 1989; Petty \& Cacioppo, 1986) that people are more likely to rely on heuristic strategies when considering issues that are not of great personal relevance, it was predicted that ease of retrieval effects would be limited to those individuals with moderate attitudes toward doctor-assisted suicide. The results of the study supported our hypothesis: Individuals with moderate attitudes were affected by their accessibility experiences in deriving judgments of attitude certainty, intensity, and importance, whereas individuals with extreme attitudes were not. ${ }^{5}$

Using a misattribution paradigm previously employed by Schwarz et al. (1991), Study 2 tested directly whether people relied on their accessibility experience in forming perceptions of their attitude toward an issue. It was predicted that participants would rely on their accessibility experience when it was diagnostic, but on the content of accessed information when the experience was rendered nondiagnostic. Consistent with our prediction, only when the subjective experience was perceived as diagnostic was it considered as a source of information in responding to questions assessing attitude certainty, intensity, and importance.

Implications of our Findings on

the Construct of Attitude Stren gth

O ur findings suggest that subjective assessments of strength-related properties are subject to contextual manipulations. In this sense, they are consistent with Bassili's (1996a, 1996b) proposal that individuals do not necessarily have direct access to judgments regarding 
the strength of their attitudes. What does this imply about the construct of attitude strength? Perhaps most important, our results indicate that investigators should be careful when characterizing individuals' attitudes if they are relying solely on subjective judgments such as attitude certainty, intensity, and importance (cf. Krosnick \& Abelson, 1992). Furthermore, our results are relevant to research that has used attitude strength-related properties as a vehicle to predict outcomessuch as attitude change and the attitude-behavior relation. We would caution that when used asa predictor of outcomes (see Petty \& Krosnick, 1995), subjective assessments of attitude certainty, intensity, and importance may themsel ves be a judgment and not necessarily a stable feature of an attitude.

One interesting possibility for future research isto use the manipulation of accessibility experiences to test findings that have been reported in the attitude strength literature. For instance, Boninger, Krosnick, and Berent (1995) examined the extent to which self-interest, social identification, and value relevance affected judgments of attitude importance. Across a variety of topics, these researchers discovered that all three constructs were significant independent predictors of attitude importance. In the future, it might be interesting to investigate whether manipulating the ease with which an individual generates arguments that support or counter their opinion (as in the studies reported in this article) can influence participants' perceptions of the relation between an attitude and their self-interest, social identification, and value relevance. O ther areas for possible investigation include assessing the extent to which accessibility experiences affect persuasive strategies (Swann, Pelham, \& Chidester, 1988) and the attention paid to (and memory for) attitude congruent and incongruent information (H oward-Pitney, Borgida, \& O moto, 1986).

Our results are also relevant to discussions concerning the extent to which attitude-relevant judgments are derived on the basis of available and salient information. In a recent article on this topic, Wilson and Hodges (1992) concluded that individuals' attitudes often vary as a function of the information that is accessible at the time of judgment. Furthermore, they suggested that the extent to which attitudes are derived on the basis of available information is moderated bystrength-related qualities, such that strong attitudes are more stable than weak attitudes ( see also Erber, Wilson, \& H odges, 1995) . O ur results are consistent with this proposal. When individuals are asked to make judgments about the importance, intensity, and degree of certainty with which theyhold an attitude, these too can vary as a function of the subjective experiences associated with recalling attitude-relevant information from memory. Furthermore, consistent with Wilson and colleagues' position (Wilson \& Hodges,
1992; Erber, Wilson, \& Hodges, 1995), the impact of accessible information in the derivation of subjective strength judgments differs as a function of properties of an individual's attitude.

Of course, we are not asserting that individuals al ways rely on their subjective experiences in deriving judgments of attitude certainty, importance, or intensity. N or are we claiming that ease of retrieval is the only source of information that individuals consider when making such judgments. Indeed, our data suggest that individuals with moderate versus extreme attitudes bring different types of information to mind when making these judgments. Furthermore, these subjective experiences are likely to be used only when theyare perceived asdiagnostic to the judgment. The aim of our research has been to demonstrate that individuals can use their accessibility experiencesin deriving these judgments and that temporarily manipulating the type and amount of information that is accessible can alter individual's metaattitudinal beliefs about the certainty, intensity, and importance of their attitudes.

In our research, we examined three different attributes of attitude strength. Although the relative ease with which attitude-relevant information came to mind altered people's perceptions of their attitudes, judgments of attitude certaintyand intensity were more sensitive to the argument generation task than were judgments of attitude importance. How might this weaker pattern of findings be reconciled with Roese and O Ison's (1994) proposition that people rely on the ease with which information comes to mind to judge the importance of their attitudes? Although judgments of attitude importance can rest on the accessibility of attituderelevant information, what it means to have had an easy or difficult time bringing this information to mind may not always be diagnostic of one's own attitude toward an issue. For example, people might infer that the ease with which attitude-relevant information came to mind is more of a function of how the issue is covered in the media than of one's attitude toward the issue.

Implications for Research

on Subjective Experiences

The present results provide additional evidence for the important role played by subjective experiences in the derivation of social judgments. There is now a large number of studies conducted in both laboratory and nonlaboratory settings that have reached a clear conclusion: Subjective accessibility experiences affect judgmental outcomes ( see Schwarz, 1998, for a review). In addition to judgments of attitude strength, ease of retrieval has been found to influence self-perceptions (e.g., Schwarz et al., 1991), group-based judgments (e.g., Rothman \& Hardin, 1997), judgments of health risks 
(e.g., Rothman \& Schwarz, 1998), and judgments of stereotypicality (e.g., Dijksterhuis, Macrae, \& Haddock, 1998). In many of these studies, researchers have moved for ward to address the question of when these effects are especially likely to occur. O ne condition that appears to enhance the impact of subjective experiences on judgment is the individual's level of involvement with the stimulus object. For instance, Dijksterhuis et al. (1998) examined the extent to which the subjective experiences associated with recalling gender stereotypic information affected a subsequent gender-relevant judgment. They found that ease of retrieval affected the later judgment, but only among individuals low in prejudice. Furthermore, Rothman and Schwarz (1998) found that the personal relevance of the issue and the judgment at hand influenced whether people relied on the ease with which health-relevant information came to mind. At the same time, however, it would be overly simplistic to assume that accessibility experiences influence judgments only when people processinformation in a superficial or heuristic manner. In some situations, subjective feeling states may be perceived as highly applicable to the judgments at hand, and therefore, people will use this information even when they are motivated to process information systematically (e.g., Rothman \& Hardin, 1997, Study3). Future research should continue to further our understanding of the conditions in which subjective accessibility effects are especially likely to occur. In addition, future research in this domain should continue to consider questionssuch as the range of these effects and the extent to which subjective experiences affect behavioral outcomes.

\section{CONCLUSION}

In conclusion, our findings suggest that subjective judgments of attitude certainty, intensity, and importance are affected by the accessibility experiences that accompany the recollection of attitude-relevant information. Furthermore, these effects are dependent on the extremity of an individual's attitude and occur only when the individual's subjective experience is diagnostic. Asthe processesinvolved in forming strength-related judgments are still not fully understood, we hope that our findingswill spark additional interest in the topics of how individuals respond to strength-related questions and the role of accessible information in the derivation of social judgments.

\section{NOTES}

1. There were no significant gender effects in either study reported in this article; thus, the data are collapsed across this dimension.

2. For ease of presentation, when we speak of argument type as an independent variable, support will refer to participants who generated arguments that supported their preexisting attitude, whereas counter will refer to participants who generated arguments that countered their preexisting attitude.

3. We conducted a factor analysis on individuals' responses to the certainty, intensity, and importance items. The results revealed a single-factor solution that accounted for $69 \%$ of the variance, further supporting the decision to create a composite index.

4. In thisstudy, we were unable to preselect participants on the basis of the extremity of their preexisting attitude. H owever, we did ask participants to report their attitude toward doctor-assisted suicide before beginning the experimental task. Given the results of Study 1, we were most interested in examining individuals with moderate attitudes toward our target issue. Thus, 26 individuals with extreme attitudes were not included in the analyses that follow. Including these individuals does not change any of the results other than to attenuate the magnitude of the effects obtained.

5. Although the results obtained in Study 1 are consistent with the premise that individuals with extreme attitudes have more accessible summar yassessments of strength-related properties, this study was not designed to directly test the accessibility of these beliefs. Integrating measures of response time into future research would allow for a more direct test of this prediction (Bassili, 1996a, 1996b; Fazio, 1995).

\section{REFERENCES}

Abelson, R. P. ( 1995) . Attitude extremity. In R. E. Petty \& J. A. Krosnick (Eds.), Attitude strength: Antecedents and consequences (pp. 25-42). Hillsdale, NJ: Lawrence Erlbaum.

Allport, F. H ., \& H artman, D. A. (1925). The measurement and motivation of atypical opinion in a certain group. American Political Science Review, 19, 735-760.

Bassili, J. N. (1993). Response latency versus certainty as indexes of the strength of voting intentions in a CATI survey. Public O pinion Quarterly, 57, 54-61.

Bassili, J. N. (1996a). The how and why of response latency measurement in telephone surveys. In N. Schwarz \& S. Sudman (Eds.), Answering questions: M ethodology for determining cognitive and communicative processes in survey research (pp. 319-346). San Francisco: Jossey-Bass.

Bassili, J. N. (1996b). Meta-judgmental versus operative indexes of psychological attributes: The case of measures of attitude strength. Journal of Personality and Social Psychology, 71, 637-653.

Boninger, D. S., Krosnick, J. A., \& Berent, M. K. (1995). The causes of attitude importance: Self-interest, social identification, and values. Journal of Personality and Social Psychology, 68, 61-80.

Chaiken, S., Liberman, A., \& Eagly, A. H . (1989) . H euristic and systematic processing within and beyond the persuasion context. In J. S. Uleman \&J. A. Bargh (Eds.) , Uninten ded thought (pp. 212-252). N ew York: Guilford.

Chaiken, S., \& Trope, Y. (Eds.). (in press). Dual process models in social psychology. N ew York: Guilford.

Dijksterhuis, A., Macrae, C. N., \& H addock, G. (1999). When recollective experiences matter: Subjective ease of retrieval and stereotyping. Personality and Social Psychology Bulletin, 25, 760-768.

Downing, J. W., Judd, C. M., \& Brauer, M. (1992). Effects of repeated expressions on attitude extremity. Journal of Personality and Social Psychology, 63, 17-29.

Eagly, A. H ., \& Chaiken, S. (1993) . Thepsychology of attitu des. Fort Worth, TX: H arcourt Brace.

Erber, M. W., H odges, S. D., \& Wilson, T. D. (1995) . Attitude strength, attitude stability, and the effects of analyzing reasons. In R. E. Petty \& J. A. Krosnick (Eds.), A ttitudestrength: Antecedents and con sequen ces (pp. 433-454). Hillsdale, NJ: Lawrence Erlbaum.

Fazio, R. H . (1995). Attitudes as object-evaluation associations: Determinants consequences, and correlates of attitude accessibility. In R. E. Petty \& J. A. Krosnick (Eds.) , Attitu de stren gth: Antecedents and conse quences ( pp. 247-282). Hillsdale, NJ: L awrence Erlbaum.

Fazio, R. H., \& Zanna, M. P. (1978). Attitudinal qualities relating to the strength of the attitude-behavior relation. Journal of Experimental Social Psychology, 14, 398-408.

Festinger, L. (1957). A theory of cognitivedissonance. Palo Alto, CA: Stanford U niversity Press. 
Haddock, G., Rothman, A. J., \& Schwarz, N. (1996). Are (some) reports of attitude strength context dependent? Canadian Journal of Behavioural Science, 28, 313-316.

H odges, S. D., \& Wilson, T. D. (1993). Effects of analyzing reasons on attitude change: The moderating role of attitude accessibility. Social Cognition, 11, 353-366.

Howard-Pitney, B., Borgida, E., \& O moto, A. M. (1986). Personal involvement: An examination of processing differences. Social Cognition, 4, 39-57.

Johnson, B. T., \& Eagly, A. H . (1989) . Effects of involvement on persuasion: A meta-analysis. Psychological Bulletin, 106, 290-314.

Kiesler, C. A. (1971). The psychology of commitment: Experiments linking behavior to belief. San Diego, CA: Academic Press.

Krosnick, J. A. (1988). Attitude importance and attitude change. Journal of Experimental Social Psychology, 24, 240-255.

Krosnick, J. A., \& Abelson, R. P. ( 1992). The case for measuring attitude strength in surveys. In J. Tanur (Ed.), Questions about questions: Inquiries into the cognitive bases of surveys (pp. 177-203). New York: Russell Sage.

Krosnick, J. A., Boninger, D. S., Chuang, Y. C., Berent, M. K., \& Carnot, C. G. (1993) . Attitude strength: O ne construct or many related constructs? Journal of Personality and Social Psychology, 65, 1132-1151.

Krosnick, J. A., \& Petty, R. E. ( 1995) . Attitude strength: An over view. In R. E. Petty \& J. A. Krosnick (Eds.), Attitude stren gth: Antecedents and consequences (pp. 1-24). Hillsdale, NJ: Lawrence Erlbaum.

Krosnick, J. A., \& Schuman, H . (1988). Attitude intensity, importance, and certaintyand susceptibility to response effects. Journal of Personality and Social Psychology, 54, 940-952.

Leippe, M. R., \& Elkin, R. A. ( 1987). When motivesclash: Issue involvement and response involvement as determinants of persuasion. Journal of Personality and Social Psychology, 52, 269-278.

Petty, R. E., \& Cacioppo, R. E. (1986). The elaboration likelihood model of persuasion. In L. Berkowitz (Ed.), Advances in experimental social psychology (Vol. 19, pp. 123-205). San Diego, CA: Academic Press.

Petty, R. E., \& Krosnick, J. A. (Eds.) . (1995) . Attitu destren gth: A ntecedents and con sequences. Hillsdale, NJ: Lawrence Erlbaum.

Raden, D. (1985). Strength-related attitude dimensions. Social Psychology Quarterly, 48, 312-330.

Roese, N. . ., \& O Ison, J. M. ( 1994) . Attitude importance as a function of repeated attitude exposure. Journal of Experimental Social Psychology, $30,39-51$.
Rothman, A. J., \& H ardin, C. D. ( 1997) . Differential use of the availabilityheuristic in social judgment. Personality and Social Psychology Bulletin, 23, 123-138.

Rothman, A. J., \& Schwarz, N. (1998) . Constructing perceptions of vulnerability: Personal relevance and the use of experiential information in health judgments. Personality and Social Psychology Bulletin, 24, 1053-1064.

Schuman, H., \& Presser, S. (1981). Q uestions and answers in attitu desurveys: Experiments on question form, wording, and context. San Diego, CA: Academic Press.

Schwarz, N. (1998). Accessible content and accessibility experiences: The interplay of declarative and experiential information in judgment. Personality and Social Psychology Review, 2, 87-99

Schwarz, N., Bless, H., Strack, F., Klumpp, G., Rittenauer-Schatka, H ., \& Simons, A. ( 1991). Ease of retrieval asinformation: Another look at the availability heuristic. Journal of Personality and Social Psychology, $61,195-202$.

Swann, W. B., Pelham, B. W., \& Chidester, T. R. (1988). Change through paradox: Using self-verification to alter beliefs. Journal of Personality and Social Psychology, 54, 268-273.

Thomsen, C. J., Borgida, E., \& Lavine, H . (1995). The causes and consequences of personal involvement. In R. E. Petty \& J. A. Krosnick (Eds.), Attitude strength: Antecedents and consequences (pp. 191-214). Hillsdale, NJ: Lawrence Erlbaum.

Tversky, A., \& Kahneman, D. (1973) . Availability: A heuristic for judging frequency and probability. Cognitive Psychology, 5, 207-232.

Wänke, M., Bless, H ., \& Biller, B. (1996). Subjective experience versus content of information in the construction of attitude judgments. Personality and Social Psychology Bulletin, 22, 1105-1113.

Wilson, T. D., \& H odges, S. D. ( 1992) . Attitudesas constructions. In L. L. Martin \& A. Tesser (Eds.), The construction of social judgment (pp. 3765). Hillsdale, NJ: Lawrence Erlbaum.

Wilson, T. D., Kraft, D., \& Dunn, D. S. (1989). The disruptive effects of explaining attitudes: The moderating effects of knowledge about the attitude object. Journal of Experimental Social Psychology, 25, 379-400.

Received N ovember 19, 1997

Revision accepted May 8, 1998 